\title{
EL CRISTIANO ERRANTE: ENTRE LA ENCRUCIJADA DISCURSIVA Y EL DESENCANTO UTÓPICO
}

\author{
Jorge Chen Sham
}

\begin{abstract}
RESUMEN
Tal y como lo desea la Ilustración, la economía política y la filosofía moral se dan de la mano en $E l$ Cristiano errante ${ }^{l}$ y sólo en esta encrucijada discursiva puede comprenderse su repercusión histórica. La ambigüedad de la crítica al estudiar sus índices genéricos nos conduce a un problema fundamental, que solo se resuelve cuando tomamos en cuenta que la narrativa de finales del XVIII y principios del XIX es un campo elaboratorio de formas discursivas y genéricas que tienen como común denominador la noción de que la literatura puede ser crítica de la sociedad y mapear la nueva realidad americana.
\end{abstract}

\begin{abstract}
As proposed by the Rationalists, political economy and moral philosopy go hand in hand in El cristiano errante and solely through an examination of it can one begin to comprehend its historical reprecussions. The ambiguity of the critique of the study, and its generic references, drive us to a fundamental problem that can only be resolved when we take into consideration that the narrative at the end of the 18th century and the beginning of the 19th the field generates discursive forms and genres that have as a common denominator the notion that literature can be a critique of society and map out a new American reality.
\end{abstract}

Repensar la vigencia de El Cristiano errante (Novela que tiene mucho de historia), publicado en 1847 en Bogotá, Imprenta Tipográfica de Espinoza², supone analizar sus componentes discursivos, con el fin de dilucidar su proceso de significación. La ambigüedad de la crítica al estudiar sus índices genéricos nos conduce a un problema fundamental. Carolina Sanabria ha analizado la incidencia en la recepción literaria que causó El Cristiano errante entre los historiadores de la literatura guatemalteca e hispanoamericana, y reafirma, en su conclusión, el carácter transformacional del texto de Antonio de José Irisarri (34). En primer lugar, sorprenden los juicios sobre la delimitación genérica, tales como novela de condición incipiente: "novela autobiográfica sin terminar" (Henríquez Ureña 1964:110) o de precursora de la corriente realístico-costumbrista: "un tipo de relato que, aunque no alcanza la categoría de novela, es sin duda germen de ésta" (Albizurez 1986:20). De ellos se vale Sanabria para afirmar que El Cristiano errante es precursor e iniciador del género novelesco y, por ello, como texto inaugural que ensaya una nueva tipología discursiva, "devela las operaciones transformacionales" (Sanabria 1992:34) en ciernes y a las cuales aquél se adhiere definitivamente dentro de la tradición narrativa con la que cuenta Irisarri. 
Precisamente, Almícar Echeverría, en su "Prólogo" a la edición de la Biblioteca Guatemalteca de Cultura Popular, debía habernos facilitado, en el apartado "Fuentes de inspiración literararia", un recuento de los estímulos literarios y de los géneros a los que apela Irisarri; sin embargo, esto no sucede, ni tampoco Carolina Sanabria las señala cuando habla de las innovaciones discursivas del texto en estudio. Para analizarlas, es necesario dar cuenta, como dijimos más arriba, del proceso de producción de El Cristiano errante, a partir de un estudio de la formación estético-literaria en la que se inserta Irisarri, porque de ella derivan las opciones discursivas y los estímulos genéricos con los que cuenta el escritor para crear su texto. Desde nuestro punto de vista, la incomprensión de tales opciones y estímulos desemboca en las apreciaciones críticas que rechazan la categoría de "novela" para el texto en estudio, aunque el mismo Irisarri la reivindique en varios lugares de su "Prólogo" autorial ${ }^{3}$ y en el subtítulo del libro muestre tal oscilación genérica; sirvan de ejemplo las palabras de Seymour Menton que ponderan la veta costumbrista-satírica:

\footnotetext{
La prueba de que esta obra no es novela es que no tiene intriga y que se nota claramente que el propósito del autor no fue el de crear una novela. El mismo Irisarri afirma que el objeto de su libro fue pintar las costumbres de su tiempo para que la gente conociera su pasado (9).
}

Si, como desea ver Menton, la novela se caracteriza por una intriga y una acción bien trabadas entre sí, El Cristiano errante adolece de esto. Entonces, ¿a qué género se adscribe? La respuesta comienza a dibujarse en el "Prólogo", en donde las declaraciones sobre lo que llama Gérard Genette "definiciones genéricas" traducen la preocupación del autor por incluir el texto dentro de una tradición. Para el crítico francés, éstas son propias de prácticas literarias en transición, ya que "on cherche à définir de telles déviations par rapport à une norme antérieure encore ressentie comme telle" (1987: 208). Así, el texto inscribe su declaración en el acápite del "Prólogo" para no dejar ninguna duda respecto de la intentio autoris: "Criticar las costumbres de mi tiempo es tan solo el objetivo de mi escrito" (23, tomo I). El verbo "criticar" al que se refiere aquí Irisarri inserta El Cristiano errante dentro del "espíritu crítico" dieciochesco que pretendía una reforma de las costumbres y pregonaba la educación como motor de todo cambio, dentro, eso sí, de la asociación entre "crítica" y verdad (Chen 1994: 8).

Dada la importancia de este "espíritu crítico", Inmaculada Urzainqui intenta, en efecto, ordenar el terreno de la práctica dieciochesca de la crítica y distingue en ella dos tipos: la "buena crítica", la de imparcialidad, sensatez, decoro, conocimiento profundo de la materia y prudencia hermenéutica; y la "mala crítica", la parcial y frívola, "la que en vez de evaluar desapasionadamente méritos y deméritos se fijaba tan solo, por exceso de severidad o de complacencia, en el lado malo o en el bueno de la obra a que se aplicaba" (1996: 862). Según la instancia autorial, El Cristiano errante se ajusta a este criterio de crítica desapasionada e imparcial, fundada sobre la razón y en un análisis pormenorizado ${ }^{4}$. Por otro lado, el prólogo autorial destaca la función pedagógica que, en el ámbito de la discursividad dieciochesca, se muestra ostensiblemente en publicaciones periódicas, sobre todo en esos periódicos con tendencia moralista y satírica, en donde constantemente se solicitaban consejos y se discutía sobre problemas de conducta y de vida cotidiana. En este marco, se explica con gran pertinencia la aparición de periódicos satíricos en los que, bajo un tono crítico, se hacía un análisis de la sociedad y de sus costumbres. Ma. Dolores Sáiz advierte que la circulación de esta prensa crítica se encuentra ligada al desarrollo del ensayo como forma discursiva que analiza problemas de actualidad y trata todos los aspectos de la vida contemporánea: 
Se ocupaban de la crítica social y de costumbres, y abordaban los problemas vinculados al desarrollo de la vida cotidiana: hábitos educativos, religiosos, diversiones, etc. (1983: 149).

Precisamente, la instancia autorial subscribe abiertamente esta temática al declarar que las analizará "criticando las costumbres de su tiempo" (23, tomo I). Por lo tanto, el texto confiesa la utilidad moral de la ficción en cuanto análisis de la sociedad, con referencia explícita a la reforma de costumbres actuales, objeto al que apunta el libro:

\footnotetext{
Tampoco se ha de ir un hombre a ocupar en hablar mal de las costumbres de sus mayores, que fueron distintas a las suyas, porque sobre ser esto una cosa de muy mala crianza por faltarse al respeto debido a los padres, ningún provecho trae a los presentes, que no son los que tienen aquellas malas costumbres ni es reforma de ellas las que le interesa (23, tomo I).
}

De esta manera, El Cristiano errante pondera su estatuto auténtico, pues "los problemas que se analizarán en ellas son reales y no obedecen a mentiras o cosas inventadas" (Almanza 1982). Como la escritura obedece a criterios de instrucción para los lectores, el escritor, en tanto historiador, desea ofrecer un cuadro lo más fiable posible y con puntual exactitud de su época, apelando a las funciones del cronista; de ahí la pregunta retórica que dirige el autor en el "Prólogo":

\footnotetext{
¿No te servirá de algo por lo menos, la relación de un testigo de vista, de un actor, de un hombre que puede descubrirte secretos importantes, manifestándote con auténticos documentos que muchos hechos que se tienen por ciertos son falsos, y que otros, de que se duda no debe dudarse [?] (24-5, tomo I).
}

Contigüidad obligada, esta reivindicación de lo histórico se acompaña, en El Cristiano errante, de una aclaración que pone en guardia al lector sobre el estatuto de lo ficcional, engañoso o fraudulento, justificando el uso que se hace del término "novela" en el título mismo del libro. ¿A qué se debe tales explicaciones? Para Shelley Yahalom, en el ámbito de la discursividad dieciochesca, se produce una serie de transformaciones entre lo canónico literario y lo no-literario (408-9); la literatura ganará en amplitud y en profundidad cuando utilice toda la gama de informaciones y de recursos provenientes de la historia, de la geografía y de las nuevas ciencias experimentales, además de la exploración de otras formas discursivas como las relacionadas con la escritura íntima (epistolarios, diarios, memorias) o la escritura periodística (periódicos, relatos de viajes, crónicas). De manera que la novela entre el último tercio del siglo XVIII y la primera mitad del XIX da cuenta de las interferencias discursivas que se producían entre lo canónico literario y lo no-literario (Yahalom 1980: 410). Las novelas dieciochescas muy pronto incorporan "la información política [y] muy pronto se unieron la información cultural, la difusión literaria, la crítica social y bibliográfica” (Urzainqui 1995: 193).

Así, los criterios de autentificación permean no solo la literatura, sino que ciertas formas discursivas pertenecientes a lo no canónico invaden la ficción literaria, de manera que las memorias, los diarios íntimos y las colecciones de cartas se introducían en textos de ficción para mostrar la autenticidad de la escritura por medio de criterios procedentes del método crítico. Este criticismo condiciona la construcción del texto de ficción, el cual debe acomodarse a las nuevas técnicas de distribución de la información y abordar el conjunto de conocimientos acerca del hombre y del universo que las nuevas ciencias experimentales planteaban (Yahalom 1980: 415). En ellas, un nuevo lugar ocupaba el hombre a la luz de las nuevas filosofías experimentales y cobraba sentido el repensar al sujeto en relación con los estímulos que emanan de su conciencia siguiendo el sensualismo lockeano ${ }^{5}$. 
A la luz de lo anterior, es necesario insertar El Cristiano errante dentro de las transformaciones de lo novelesco en el siglo XIX hispanoamericano, en un momento en el que apenas empezaban a demarcarse los nuevos países y se creaban las condiciones necesarias para la constitución de las nacionalidades. En estos primeros años de la Independencia, las prácticas discursivas estarán todavía marcadas por una cultura ilustrada, por lo que las formas novelescas evolucionarán dentro del canon impuesto por la tradición dieciochesca. Prueba de ello es El Cristiano errante de Irisarri, el cual ensaya el tipo de novela moderna como crítica de una época y de una sociedad. La nueva conciencia "criolla", nos parece, busca sus huellas de identidad en la construcción de un capital simbólico en el que el saber y la erudición y la acumulación de capital están en el mismo nivel (González 2000: 46). Con la graficación del mapa del nuevo continente, el cual es reflejo de las relaciones económicas que poseía el padre de Romualdo, Irisarri muestra la nueva correlación de fuerzas del mercantilismo hispanoamericano:

\footnotetext{
En un año Romualdo hizo los inventarios, y los balances de las cuentas de la casa que tenía con diversas otras de comercio de Londres, de Cádiz, de Madrid, de Filadelfia, de Boston, de Baltimore, de Jamaica, de La Habana, de México, de Veracruz, de Oaxaca, de Lima, de Guayaquil, de Valparaíso, de Santiago de Chile, de Coquimbo y con los gobiernos de México y el Perú [...] (71, tomo I).
}

Por ello, si la novela de Irisarri comienza como historia puntual y cronológica de Romualdo de Villapedrosa, escrita en tercera persona y narrada en forma retrospectiva a la manera de las crónicas históricas, más adelante se adscribe, con la dimensión cartográfica que despliega las redes capitalizadoras del patrimonio de Romualdo, a la novela de aventuras y al relato de viaje, por dos razones: a) una razón familiar y diegética: la ampliación de los territorios recorridos por Romualdo se debe a las necesidades comerciales que el manejo de su herencia requiere; y b) una razón filosófica y discursiva: al texto le interesa poner al protagonista dentro de un punto de vista fijo y conclusivo, cuando ha terminado sus estudios formales y se ha forjado un carácter con el cual podrá hacer frente a sus pruebas iniciáticas. Desarrollemos. Desde este punto de vista, pertenece El Cristiano errante a la novela de peregrinos, un subgénero de la novela bizantina en las que las aventuras marítimas, los lances y las peripecias están a la orden del día y son pruebas que conducen al peregrino hacia su búsqueda de verdad (Rey 1982: 102). Desde el momento en que Irisarri le pone a Romualdo de Villapedrosa el mote de "cristiano errante", lo concibe ajustándose a la novelas de peregrinaje del Siglo de Oro, en las que el peregrino, cristiano por antonomasia, debía viajar en procura de una doble recompensa, espiritual y amorosa (102); veamos lo que dice el narrador:

\footnotetext{
[...] este viaje no fue emprendido por consecuencia de ningunos amores, sino porque Dios había destinado a este cristiano para que pasase su vida visitando cortes y cortijos, unas veces por una razón y otras por otra. Comenzaremos, pues, a ver cuál, [sic] fue el principio de la vagancia o de la vagamundería, como decimos, por acá, de nuestro vagamundo Romualdo (70-1, tomo I. La cursiva es del autor).
}

Aunque el narrador extradiegético destaca al principio de la novela que los motivos del viaje emprendido por Romualdo corresponden más bien al primer tipo de recompensa, con el desarrollo de su relato comprobamos también la pertinencia del segundo; el viaje será motivado por razones sentimentales, cuando Romualdo se enamora de Dorila y bajo este impulso desea finiquitar su negocio en la capital mexicana y regresar a Oaxaca (240, tomo II) ${ }^{6}$. Por otra parte, Romualdo inicia este viaje a los 20 años (71, tomo I), edad en la que era común que los jóvenes en proceso de aprendizaje hicieran los grandes periplos por la Europa del siglo 
XVIII (Simón 1993-94: 104-5). Indica la novela que lo hace por mandato paterno, ya que como albacea de su padre debe encargarse de los negocios familiares y salvar el patrimonio ante una riesgosa operación de banca y de comercio que lo obliga a trasladarse a Ciudad de México. Romualdo debe mostrarse como un hombre capaz no solo de solventar los obstáculos físicos del viaje, sino también de saber tratar, con madurez y con la urbanidad que proporciona su condición, a las gentes. Ejemplo de lo anterior es el primer intento de Romualdo por llegar a México; muestra la deuda de El cristiano errante con la novela de peregrinos, pues tiene todas las características de una aventura marítima, con acto de piratería, saqueo del bergartín "Esclavo de María", captura del equipaje y posterior rescate de los prisioneros ${ }^{7}$. Cuando Romualdo es liberado, vuelve a su casa y recibe las muestras de cariño y de afecto de parientes, amigos y conocidos. En este momento, el narrador reproduce el pensamiento de Romualdo ante tantas visitas recibidas en esos días y nos informa que éste conocía las convenciones sociales y las exigencias que las reglas del decoro y del comportamiento exigen, haciendo que los hombres enmascaren continuamente sus verdaderas intenciones en el trato social; la disimulación y el fingimiento están a la orden del día:

\footnotetext{
Romualdo desde entonces, y desde mucho antes, sabía perfectamente que el que no aprende a fingir en esta vida, no vive bien; y por muy honrado que él fuese, no podía ni debía parecerlo más que la doncella más encogida, que la viuda más recatada, que el monje más austero, que pasan sus honrados y pacíficos días disimulando, fingiendo que no entienden lo que entienden muy bien, y dando a entender que sienten lo que no sienten.

El mayor grado de civilización, decía el buen Romualdo no se conoce sino en saber fingir más de lo que finge un salvaje [...] (102-3, tomo I).
}

Constantemente, el narrador extradiegético hace largas digresiones para comentar los acontecimientos vividos por Romualdo. Estas intervenciones del autor-narrador, si tienen en primer lugar la función de dialogar con el lector para crear una relación de complicidad y voluntad continua de sorpresa (Bancaud-Maënen 1998: 80) ${ }^{8}$, desarrollan una dinámica narrativa en la que constantemente se interrumpe el relato (y la intriga por supuesto) para que el narrador converse con el lector sobre diversos temas de actualidad o de reflexión (Bancaud-Maënen 81). Asegurada la relación temática, y gracias a la técnica de la asociación de ideas, la digresión del narrador aborda, en este caso, el tema del engaño desde una perspectiva pedagógica y filosófica pesimista, con un tono que nos invita a la discusión y a la corrección moral:

\footnotetext{
El engaño es precisamente el que más contribuye a nuestra felicidad; quitemos el engaño, quitemos la ilusión y nuestra miserable vida se hace intolerable (106, tomo I).

[...] si el engaño se ha hecho indispensable para conseguir por medio de él nuestra crianza, nuestra educación y la felicidad de nuestra vida social en nuestras relaciones más íntimas, preciso era que no faltase en todos los demás negocios nuestros [...]; y la verdad es, que las más veces, tratando de engañar a los otros, sólo nos engañamos a nosotros mismos [...] (115-6, tomo I).
}

La condena es clara en materia de conducta del hombre y de la función del "contrato social" que nos ofrece la sociedad", ya que Irisarri esgrime que desde nuestro nacimiento se nos enseña a mentir y a disimular para vivir civilizadamente ${ }^{10}$. Por otra parte, esta necesidad de integrar la reflexión filosófica en el terreno de la ficción literaria tiene como finalidad la polémica abierta y franca con el lector para que se discutan problemas puntuales que sirvan de debate, tal y como existían en los periódicos europeos del XVIII, con esa necesidad de diálogo intelectual y de inquietud pedagógica para desterrar errores y proponer una reforma de la 
cultura, que a la postre llevaría a los ilustrados a desengañar y a reformar. Por su parte, Shelly Yahalom señala cómo el ensayo filosófico y la guía moral, los principales géneros del discurso moral, se integran a lo literario con un objetivo doble: "apprendre non seulement à bien écrire mais aussi à bien penser" (418). Muchas de las digresiones de El cristiano errante se ajustan a esta finalidad pedagógica por medio del tono de polémica que sustentan.

Sin embargo, hay otras digresiones que, en lugar de insertarse dentro de la novela filosófica, apelan al relato de viajes dieciochesco. Al proponernos, en el apego a la curiosidad científica y a la seducción por lo ignoto (Lafarga 1994: 177-81), un viaje de un rico criollo nacido en esta América hispana hacia tierra lejanas y desconocidas, el viaje satisface un doble requerimiento: conocimiento del mundo y descubrimiento del sujeto gracias a su inserción en el mundo (Picard 1981: 117), lo cual se logra con la anotación de las impresiones del medio y de las gentes, mezcladas con reflexiones personales.

He aquí expuesto lo que es en esencia El Cristiano errante: unas memorias de viaje en el sentido dieciochesco, en el que la literatura se enriquece con la imbricación de las curiosidades científicas y de las reflexiones filosóficas (Lafon 1982: 307), para un público "erudito" cada vez más exigente (Lafarga 1994: 180). El interés por los relatos de viajes y por las publicaciones periódicas de tipo erudito, que informaban sobre los nuevos avances y descubrimientos, puede explicar estas demandas cognoscitivas, pues se trataba de una verdadera

\footnotetext{
[...] curiosité pour les espaces inconnues, fantasmes érotiques, goût pur l'explication rationnelle et technique, sentiment de l'importance des possessions matérielles, idéologies sentimentales de la 'nature'. Il est bien évident que ces différentes formes n'ont été distinguées que pour l'analyse [...] [et pour] remplir à la fois plusieurs de ces attentes (Lafon 1982: 310).
}

El viaje por tierra hacia México le permite a Irisarri describir una ruta que pasa por los Altos de Guatemala y su capacidad de observación aquí se nutre de una "curiosidad" que anima su empresa; ya involucra aquí un espíritu crítico que le permite analizar, como deseaba otro gran relato de viajes del siglo XVIII, las Cartas marruecas, "religión, clima y gobierno" (Cadalso 1983: 77):

\begin{abstract}
Atravesó, pues, los grandes pueblos hasta Quezaltenango, capital de Los Altos, deteniéndose en Mixco, en Chimaltenango, Sumpango, en Comalapa, en Sololá y Totonicapán, lo que le pareció conveniente para formar alguna idea de aquellas poblaciones, que no dejan de presentar objetos dignos de un viajero, que no viaja sólo por atravesar un camino. Halló en todos aquellos lugares una vida, una actividad, un movimiento de civilización, que no esperaba hallar [...] (127-8, tomo I).
\end{abstract}

Romualdo se presenta, entonces, como un perspicaz viajero que, aunque tiene un interés privado y personal para hacer la travesía, también se muestra receptivo para el estudio de los pueblos que atraviesa. Por ejemplo, el ilustrado Gaspar de Jovellanos (1744-1811), en su "Discurso dirigido a la Real Sociedad del País de Asturias, sobre los medios para promover la felicidad en aquel principado"11, rechaza la banalidad y la futilidad en los objetivos del viajero cuando sus observaciones no se acompañen del criticismo ilustrado, y lo que es aún más grave, cuando la finalidad del viajero radique únicamente en un interés personal de un viaje sin método y poco sistemático:

Para conocer la situación de una provincia no basta haber vivido en ella largo tiempo [...]. Tampoco basta haberle recorrido de un cabo al otro, si esto no se hizo inquiriendo, observando y apuntando lo mas notable. El que viaje solo por divertirse, el que atr[a]viese muchas veces un país sin mas objeto que el de atender a sus particulares negocios, solo podrá decir lo que ha visto (1952: 442. Las cursivas son nuestras). 
El apunte de las observaciones tiene aquí un objetivo reivindicativo clarísimo. El viajero, en tanto observador fidedigno y testigo ocular de una realidad desconocida e inédita a sus ojos, describe las costumbres y las instituciones de los lugares que recorre anotando toda la información pertinente para la comprensión del lector. Llaman poderosamente la atención las descripciones de los pueblos indígenas laboriosos, con orden, limpieza e industria que hace Romualdo:

\begin{abstract}
Encontró [Romualdo] aquellos indios laboriosos, inteligentes, ágiles, despiertos, bien formados, robustos, aplicados a la agricultura, al comercio, a las artes, como si fuesen de otra raza de la que puebla la América meridional. Entre ellos, los caciques y los que se llaman principales y forman la aristocracia indígena, habían muchos tan civilizados como los que más de otras razas del país [...]. En general, los pueblos de aquellos indios eran aseados, las casas bien edificadas y cómodas, con sus muebles necesarios. En unas partes se dedicaban al cultivo del algodón, al hilado el tejido de esta materia: en otras partes se empleaban a la crianza de ganado lanar, cuya lana hilaban y tejían, no sólo para el surtido de sus pueblos, sino para formar un artículo de comercio que llevaban a expender a largas distancias: en otras partes se ocupaban casi todos los habitantes, en la carpintería, y con los pinos y cipreses de aquellos montes, hacían artesas, sillas, escaños, mesas, catres, y todas las demás piezas del maneje ordinario de una casa [...] (128-9, tomo I).
\end{abstract}

La imagen de los indígenas y de las tierras americanas que nos presenta El Cristiano errante contrastan con el estereotipo difundido por el naturalista francés conde de Buffon y el naturalista holandés Cornelius de Pauw ${ }^{12}$, quienes, en sus trabajos sobre las ciencias del carácter físico (del griego physis) y la historia natural, relacionaban la naturaleza con los comportamientos humanos. Para ellos, como lo explica Browning, "el continente americano era esencialmente un territorio degenerado, malsano, incapaz de sostener ninguna clase de vida sana [...] el nuevo mundo no podía desarrollar razas vigorosas" (1993: 266); es decir, las plantas y los animales se degeneraban en este continente; lo mismo sucedía con los seres humanos. Por el contrario, la descripción del territorio ofrecida por Irisarri contradice el esterotipo fundante de la barbarie americana, pues ni la selva ni la montaña hacen sucumbir a los hombres, sino que ellos permiten que los indígenas exploten sus recursos naturales, con la creación de trabajo, industria y comercio; por lo tanto, en este espacio puede florecer la civilización. Es más, el propio Irisarri por boca de Romualdo refuta esa imagen negativa del continente en el capítulo siguiente, en donde se expone todo un debate sobre la función y la utilidad del viaje y se fustiga a aquellos historiadores y naturalistas que menospreciaban la realidad americana ${ }^{13}$. Romualdo, como buen viajero imbuido en el espíritu dieciochesco, sabe analizar con juicio y con imparcialidad crítica las peculiaridades de los lugares visitados, relacionando el clima y los accidentes orográficos con la flora y la fauna:

\begin{abstract}
Finalmente, si Ud. va examinando atentamente todos los objetos que se presentan desde aquí hasta México, podrá Ud. hacer una abundante colección de observaciones muy exactas, para convencer a todo el mundo con hechos auténticos de que la supuesta degeneración de los animales y de plantas que se trajeron de Europa a América, no tiene otro principio que el haberse observado que en alguno de estos lugares, o porque había demasiado frío o porque había demasiado calor, no se daban los frutos como se dan en la temperatura que les conviene; del mismo modo que en Viscaya no se dan ciertos frutos que en Andalucía, ni en Valencia, ni en la Noruega ni los que se cosechan en Italia (157).
\end{abstract}

Las peculariades del territorio y de lo que es, en El Cristiano errante, una verdadera historia natural de Guatemala le permiten a Irisarri hacer un inventario de plantas, animales, pueblos, actividades y tipos de bosque, que llaman la atención por su tono de catálogo erudito y "voluntad de coleccionar para luego exponer los bienes" (González 2000: 42). En este 
contexto, los nuevos avances de las disciplinas como la botánica, la minerología, la geografía, la química, la economía política y la física pretendían una mayor comprensión del mundo, y, al convocarlas el relato de viajes en su seno, también permiten la transformación de la literatura en cuanto objeto de conocimiento, "pues toda obra literaria auténtica traduce una experiencia humana y dice algo acerca del hombre y del mundo" (Aguiar e Silva 1979: 71). No se trata de una mera necesidad de ampliar el conocimiento humano con el ensanchamiento del mundo conocido, sino que, en nuestro caso, se produce una verdadera reivindicación de lo autóctono americano, propio e inherente a estas tierras; las palabras de Romualdo traducen admiración ante la incomprensión y la ignorancia europeas que critica con mirada sesgada. Romualdo describe con una sensibilidad "criolla" que mapea la realidad guatemalteca en sus accidentes y peculiaridades:

\begin{abstract}
Ud. observará que en este pueblo de Mixco, se dan granos que en Europa se producen en unas latitudes mucho más altas, supliendo la elevación del terreno sobre el nivel del mar, a la diferencia de la temperatura ocasionada por la naturaleza de las zonas geográficas astronómicas. Seguirá Ud. caminando hacia el norte, y encontrará más calor o más frío, el trigo o el maíz, el pino o el plátano, según suba o baje, y no según se aleje de la línea equinoccial y se acerque al trópico de cáncer. Si toma Ud. el camino de la costa, atravesará selvas inmensas, que no le dejarán ver el sol a ninguna hora del día [...]. Por allí encontrará Ud. la caña de azúcar, el bálsamo, el caco, la zarzaparrilla, el algodón, la vainilla, el benjuí, el liquidámbar u "ocozotl”, el hule o caucho, el "nacazcolot" o "dividiv", y, en fin, las plantas, gomas, resinas y frutos [...] (157-8, tomo II).
\end{abstract}

Sin embargo, esta reafirmación de lo autóctono guatemalteco se amplía con la descripción de las ciudades de Oaxaca, Puebla y México, en las que sobresalen el grado de refinamiento, las ventajas de la vida urbana, las industrias y la opulencia de sus costumbres, de manera que la descripción del campo y de las montañas guatemaltecas y sus pueblos indígenas tienen mucho en común con ese despliegue erudito sobre espacio urbano mexicano. Por tal razón, este mapa de Mesoamérica en el que reinan el trabajo, el orden y la prosperidad, muy propios de los objetivos que la Ilustración se propone en materia de prosperidad y felicidad de los pueblos (Chen 2002), contrasta con una serie de digresiones del propio narrador extradiegético, las cuales expresan un punto de vista pesimista y degenerativo de la situación actual americana, como si Irisarri estuviera mirando nostálgicamente el pasado y criticando duramente la realidad presente. John Browning plantea en forma acertada el problema:

\footnotetext{
¿por qué en 1846 se le ocurre a Irisarri escribir memorias de los últimos días del imperio, donde la época colonial aparece retratada en forma idílica, como una utopía de tranquila prosperidad? ¿Por qué le agrega a su escueto argumento novelesco cantidades de digresiones donde entre otros muchos temas se nos habla de la tranquilidad y prosperidad de los pueblos indígenas de Guatemala, del alto nivel de civilización de Oaxaca, de la opulencia e industria de Puebla y de México? (1993: 268).
}

Browning nos habla de un desencanto y en las digresiones que comentamos surge, precisamente, una crítica a los excesos y a los vicios que encuentra el narrador; Irisarri apunta hacia los rasgos morales e intelectuales de la época actual:

En el comercio, en la política, en todas las transacciones humanas, hasta en las domésticas, hallamos esta especie de guerra que nos hacemos los mortales mientras vivimos; guerra, como en todas las guerras, en que cada cual hace a otro el mal que puede, buscando su propia ventaja; en que todas las celadas, todos ardides, todos engaños, todo egoísmo, todo [sic] hostilidad para el pobre prójimo. Examinemos bien nuestro modo de proceder en esta sociedad que llamamos humana, y que no debíamos llamar sino leonina, porque cada uno de nosotros queremos ser el león en ella, y sacar para nuestro individuo toda la ventaja, sin dejar ninguna al socio (88-9, tomo I). 
Observemos con atención el duro cuestionamiento hecho por Irisarri: ataca vicios y abusos que conducen al hombre a su envilecimiento y degeneración cuasi animal. Plantea un malestar: el hombre contribuye a su destrucción, cuando sólo piensa en su bienestar propio, acentuando el fanatismo, la crueldad y la ceguera de aquellos hombres preocupados más por el interés individual que por el colectivo, lo que la Ilustración española llamaba "la convivencia de los hombres" en una sociedad, pensada en términos de una corporación o una compañía mercantil con socios que tienen los mismos objetivos, la prosperidad colectiva. Esto es válido también para el pensamiento de Irisarri, ya que el discurso moral se deja contaminar por el discurso mercantil y la economía se transforma en ciencia de la organización social, como sucede en el pensamiento ilustra$\mathrm{do}^{14}$. José Antonio Maravall destaca que, para el siglo XVIII, la fuerza del interés individual no debe reñir con los de la sociedad, ya que el motor que impulsa al hombre hacia la felicidad es también colectivo:

\footnotetext{
El interés es, por una parte, la fuerza moral interna para que el hombre se gobierne a sí mismo: "cada uno sabe gobernar sus propios negocios", por lo que no se puede someter a tutela a toda una nación [...]. Por otra parte, éste es también el más seguro resorte para que la autoridad pueda utilizarlo en el gobierno general de todos: "el interés es el timón con que se gobiernan los hombres". Lo cual equivale a sostener que el interés posee de suyo una tendencia social, y si bien es base de la actividad individual, no lo es menos de la existencia misma del cuerpo social. La armonía entre estos dos aspectos es incuestionable (Maravall 1979: 315).
}

Irisarri condena, por lo tanto, la degeneración de los móviles particulares y subraya, en la cita puesta más arriba, bajo la denominación de "transacciones humanas" y el apelativo de "socio", que la sociedad funciona como una empresa mercantil en perfecto arreglo con intereses colectivos. La sensibilidad ilustrada se deja contaminar de un pensamiento burgués y esto nos parece pertinente en la medida en que Romualdo se presenta como un comerciante y como un hombre con espíritu crítico. Con sus palabras, Romualdo fustiga la degeneración de toda cooperación entre individuos:

\footnotetext{
Esa noción de "socios" engendra el gran entusiasmo de saber que si se trabaja, si se hacen esfuerzos que benefician a los demás, son también beneficiosos necesariamente para sí; y a la inversa es no menos cierto también: quien trabaja en su propio interés trabaja para los demás. Tal es el "descubrimiento" [...] que alcanza el hombre del siglo XVIII y del cual saca energías para su empresa (Maravall 1979: 311-2).
}

Es decir, cada uno debe poner sus esfuerzos y sus luces en la consecución del Bien para todos los miembros de una sociedad. De esta manera, la utilidad se transforma en una empresa que vigoriza la cooperación y los altos valores morales de los hombres. Lo contrario sería el engaño que embrutece a los hombres; veamos lo que dice el narrador de El Cristiano errante:

\footnotetext{
El engaño es precisamente el que más contribuye a nuestra felicidad; quitemos el engaño, quitemos la ilusión y nuestra miserable vida se hace intolerable. No engañemos a otros; ni nos dejemos engañar de nadie; no nos engañemos a nosotros mismos, desterremos las ilusiones; no vivamos sino con las realidades, y adiós esperanzas lisonjeras, adiós grandiosos proyectos, adiós felicidad, adiós felicidad. No nos queda sino un presente que nada tiene de feliz y un futuro que no debe ser mejor que el presente (106, tomo I).
}

Abiertamente, El Cristiano errante plantea el problema en términos pesimistas, como si no hubiera más esperanza de que los hombres se corrijan y los defectos morales sean los 
que dominen ahora. Por eso, una crisis se cierne hoy en día y se desarrolla en términos de una corrupción de las virtudes; es necesaria, entonces, una reforma de costumbres para acabar con la decadencia reinante. El discurso moralista de la Ilustración hace aquí su aparición y, en esa conjunción entre lo económico y lo filosófico, exagera el tono de atraso y de decrepitud de la realidad actual. Contrasta, por ello, con el espacio idílico y con la organización de los pueblos indígenas guatemaltecos y la bonanza económica de las ciudades mexicanas que recorrió y por las que atravesó Romualdo. Este objetivo de El Cristiano errante queda explícito en el mismo "Prólogo": "para que sea bueno escribir criticando las costumbres del tiempo en que uno vive" (23, tomo I). Para lograrlo, el texto se asegura ese rasgo de autenticidad al proponernos el viaje fiable y objetivo de Romualdo, testigo fiel y cronista puntual, con el fin de que haya un contraste con la decadencia actual, expuesta por el narrador a modo de digresiones autoriales. Tal y como lo desea la Ilustración, la economía política y la filosofía moral se dan de la mano en El Cristiano errante ${ }^{15}$ y sólo en esta encrucijada discursiva puede comprenderse su repercusión histórica.

\section{Notas}

1. Un desarrollo amplio de estas ideas se puede encontrar en los trabajos de Maravall y en los dos libros míos que están en la bibliografía.

2. Publicado primeramente en forma de entregas, lo cual es usual en la época, en el periódico homónimo bogotano El cristiano errante, entre el 8 de agosto de 1846 y el 6 de marzo de 1847.

3. Indica lo siguiente: "Quiero que sepas muy bien sabido que la única intención que he tenido al escribir esta novela histórica, ha sido la de pintar nuestras costumbres como ellas son y como las encontró Romualdo desde México hasta Buenos Aires con el poco más en unas partes, y el poco menos en otras, que de la misma novela va resultando" (30, tomo I. Las cursivas son nuestras).

4. Ésta la distingue de la crítica personal, la de fines partidistas y que destaca los elementos más ridículos y negativos (Urzainqui 1986: 864); por eso, ella separa la crítica del libelo o panfleto.

5. Recordemos que John Locke (1632-1704) plantea, en su Ensayo sobre el entendimiento humano (1690), que el único conocimiento posible es por medio de las percepciones de los sentidos: "las sensaciones y los estímulos del mundo externo dejaban sus marcas y huellas [en la mente humana], originando de este modo pensamientos e ideas" (Mason 1995: 76).

6. Es más, el viaje a Chile será el obstáculo para que ambos amantes se unan, ya que el viaje es un impedimento que posterga la consumación del amor; por ello, El Cristiano errante posee un núcleo de novela sentimental (Rey 1982: 69-70).

7. Señala John Browning, en su artículo de 1970, que tanto a la edición chilena (Santiago de Chile, 1929) como a la edición guatemalteca (1960) les hacen falta unas páginas que describen los días que pasó Romualdo como prisionero de la marina inglesa (620-5).

8. Las extensas digresiones del narrador, nos parece, son uno de los elementos que más perjudica para que los críticos de El Cristiano errante acepten su adscripción al género novelesco; pero se han olvidado de que, dentro de las novelas dieciochescas, éstas eran muy comunes y aceptadas por los lectores.

9. El mismo Irisarri hace aquí una mención al Contrato social de Jean-Jacques Rousseau (104, tomo I). 
10. Para el lector de la literatura dieciochesca, esta actitud pesimista se encuentra en uno de los textos fundamentales de la novela epistolar de viajes: las Cartas marruecas de José Cadalso.

11. Discurso que pronuncia Jovellanos en 1781 ante la Sociedad Económica de Amigos del País del Principado de Asturias.

12. Geroges Louis Leclerc, conde de Buffon (1707-1788), escribió la Histoire naturelle, en 36 volúmenes (1749-1789). En esta obra "il se montra un excellent observateur de la nature et eut l'intuition de la transformation lente de l'univers et de l'évolution des especès végétaux et animaux sur la terre" (Larousse, Enciclopedique en couleurs, 1328, tomo III). Por su parte, Cornelius de Pauw (1739-1799) escribe Recherches philosophiques sur les Américains (1768-1770), en la que continúa los trabajos de Buffon.

13. Hay que señalar que, en este capítulo VI, entre los autores detestables se encuentra el naturalista Pauw (155, tomo II).

14. Para un desarrollo de estos planteamientos, el lector puede consultar Maravall (1968).

15. Un desarrollo amplio de estas ideas se puede encontrar en los trabajos de Maravall y en los dos libros míos que están en la bibliografía.

\section{Bibliografía}

Aguiar e Silva, Vítor. 1979. Teoría de la literatura. 3a. reimpresión Madrid: Editorial Gredos.

Albizúrez, Francisco y Catalina Barrios. 1986. Historia de la literatura guatemalteca. Guatemala: Editorial Universidad de Guatemala.

Almanza, Lázaro. 1981. "Notas sobre la voz novela en Feijoo y en la literatura de su época". II Simposio sobre el Padre Feijoo y su siglo. Tomo II. Oviedo: Centro de Estudios del Siglo XVIII: 197-203.

Bancaud-Maënen, Florence. 1998. Le roman de formation au XVIIIè siècle en Europe. París: Éditions Nathan.

Browning, John. 1970. “El cristiano errante de Antonio José de Irisarri: su génesis, su acogida y sus "páginas perdidas"”. Revista Iberoamericana. 73: 613-27.

1993. "La historia en la literatura y la literatura en la historia". Káñina, Revista de Artes y Letras de la Universidad de Costa Rica. 17 (1): 265-71.

Cadalso, José. Cartas marruecas-Noches lúgubres. 1983. 7a. edición. Madrid: Editorial Cátedra.

Chen Sham, Jorge. 1994. "El criticismo de los novatores: motor de la primera biografía cervantina, escrita por Gregorio de Mayáns”. Revista de Filología y Lingüística de la Universidad de Costa Rica. 20 (2): 7-17. 
1999. “Fray Gerundio de Campazas" o la corrupción del lenguaje: Sátira y escamoteo autorial. San José: Editorial de la Universidad de Costa Rica.

2002. La comunidad nacional "deseada": la imposible imparcialidad política de "Cartas marruecas". San José: Editorial de la Universidad de Costa Rica/ Centro Cultural de España, por aparecer.

Echeverría, Almícar. 1960. "Prólogo". El Cristiano errante (Novela que tiene mucho de historia). Guatemala: Ministerio de Educación Pública. v-xxx.

Genette, Gérard. 1987. Seuils. París: Éditions du Seuil.

González Stephan, Beatriz. 2000. "Del catálogo a la escritura historiadora: Archivo imperial y afirmación criolla". Actas del Simposio Hacia la comprensión del 98: Representaciones finiseculares en España e Hispanoamérica. Jorge Chen Sham (Ed.). San José: Editorial de la Universidad de Costa Rica: 35-54.

Henríquez Ureña, Pedro. 1964. Las corrientes literarias en la América hispánica. 3a. edición. México, D.F.: Fondo de Cultura Económica.

Irisarri, Antonio de José. 1960. El Cristiano errante (Novela que tiene mucho de historia). 3 Tomos. Guatemala: Ministerio de Educación Pública.

Jovellanos, Gaspar Melchor de. 1952. Obras publicadas e inéditas. Tomo II. Madrid: Real Academia Española.

Lafarga, Francisco. 1994. “Territorios de lo exótico en las letras españolas del s. XVIII”. Anales de Literatura Española. 10: 173-92.

Laffon, Henri. 1982. "Sur la description dans le roman du XVIIIè siècle". Poétique. 51. 303-13.

Maravall, José Antonio. 1968. "Cabarrús y las ideas de reforma política y social en el siglo XVIII”. Revista de Occidente. 69: 273-300.

1979. “Espíritu burgués en la Ilustración española”. Hispanic Review. 47(3): 291-325.

Menton, Seymour. 1960. Historia crítica de la novela guatemalteca. Guatemala: Editorial Universitaria.

Picard, Hans Rudolf. 1981. "El diario como género entre lo íntimo y lo privado". 1616: Anuario de la Sociedad Española de Literatura General y Comparada. 4: 115-22.

Rey Hazas, Antonio. 1982. "Introducción a la novela del Siglo de Oro, I (Formas de narración idealista)". Edad de Oro 1: 65-105. 
Sáiz, Ma. Dolores. 1983. Historia del periodismo en España: 1. Los orígenes. El siglo XVIII. Madrid: Alianza Editorial.

Sanabria, Carolina. 1992. "El cristiano errante: ¿Novela que tiene mucho de historia o historia que tiene mucho de novela? Consideraciones teóricas sobre el discurso crítico contemporáneo". Káñina, Revista de Artes y letras de la Universidad de Costa Rica. 16 (2): $31-8$.

Simón Schuhmacher, Lioba. 1993-94. "El viaje con finalidad educativa: ejemplos de la literatura europea de la Ilustración”. Cuadernos de Estudios del Siglo XVIII. 3-4: 103-15.

Urzainqui, Inmaculada. 1995. "Autocreación y formas autobiográficas en la prensa crítica del siglo XVIII". Anales de Literatura Española. 11: 193-226.

1996. "Las 'personalidades' y los malos modos de la crítica en el siglo XVIII". Ese siglo que llaman ilustrado. Joaquín Álvarez Barrientos y José Checa Beltrán (Eds.). Madrid: CSIC: 859-73.

Yahalom, Shelly. 1980. "Du non-littéraire au littéraire: Sur l'élaboration d'un modèle romanesque au XVIIIè siècle". Poétique. 44: 406-21. 